\title{
Can Thoracic Ultrasound on Admission Predict the Outcome of Critically Ill Patients with SARS-CoV- 2? A French Multi-Centric Ancillary Retrospective Study
}

Gary Duclos Florian Bazalguette $\cdot$ Bernard Allaouchiche $\cdot$ Neyla Mohammedi $\cdot$ Alexandre Lopez

Mathieu Gazon · Guillaume Besch • Lionel Bouvet • Laurent Muller • Gauthier Mathon •

Charlotte Arbelot $\cdot$ Mohamed Boucekine $\cdot$ Marc Leone $\cdot$ Laurent Zieleskiewicz

Received: December 16, 2020 / Accepted: March 10, 2021 / Published online: April 14, 2021

(C) The Author(s), under exclusive licence to Springer Healthcare Ltd., part of Springer Nature 2021

\section{ABSTRACT}

Introduction: Severe acute respiratory syndrome coronavirus 2 (SARS-CoV-2) outbreaks have led to massive admissions to intensive care units (ICUs). An ultrasound examination of the

Supplementary Information The online version contains supplementary material available at https:// doi.org/10.1007/s12325-021-01702-0.

G. Duclos $(\varangle) \cdot$ N. Mohammedi · A. Lopez .

C. Arbelot - M. Leone - L. Zieleskiewicz

Department of Anesthesiology and Intensive Care Unit, Aix Marseille University, Assistance Publique Hôpitaux de Marseille, Nord Hospital, Marseille, France

e-mail: gary.duclos@ap-hm.fr

F. Bazalguette $\cdot$ L. Muller

CHU de Nîmes-Caremeau, Service Réanimation et Surveillance Continue, Pôle ARDU (anesthésie, réanimation, douleur, urgences), 30029 Nîmes cedex, France

B. Allaouchiche - G. Mathon

Hospices Civils de Lyon, Centre Hospitalier LyonSud, Service de Réanimation, 69310 Pierre-Bénite, France

B. Allaouchiche

Université Claude, Bernard-Lyon-1, Lyon, France

B. Allaouchiche

Université de Lyon, VetAgro Sup, Campus

Vétérinaire de Lyon, UPSP 2016.A101, Pulmonary

and Cardiovascular Agression in Sepsis APCSe,

69280 Marcy l'Étoile, France thorax is widely performed on admission in these patients. The primary objective of our study was to assess the performance of the lung ultrasound score (LUS) on ICU admission to predict the 28-day mortality rate in patients with SARS-CoV-2. The secondary objective was to asses the performance of thoracic ultrasound and biological markers of cardiac injury to predict mortality.

\author{
M. Gazon \\ Département d'Anesthésie et Réanimation and \\ Centre de Recherche Clinique, Groupement \\ Hospitalier Nord, Hospices Civils de Lyon, Lyon, \\ France \\ G. Besch \\ Department of Anesthesiology and Intensive Care \\ Medicine, University Hospital of Besancon, \\ Besancon, France \\ G. Besch \\ EA 3920, University of Franche-Comte, Besancon, \\ France \\ L. Bouvet \\ Service d'Anesthésie Réanimation, Groupement \\ Hospitalier Est, Hospices Civils de Lyon, Lyon, \\ France \\ L. Bouvet \\ Université de Lyon, VetAgro Sup, Campus \\ Vétérinaire de Lyon, UPSP 2016.A101, Pulmonary \\ and Cardiovascular Aggression in Sepsis, \\ 69280 Marcy l'Étoile, France
}


Methods: This multicentre, retrospective, observational study was conducted in six ICUs of four university hospitals in France from 15 March to 3 May 2020. Patients admitted to ICUs because of SARS-CoV-2-related acute respiratory failure and those who received an LUS examination at admission were included. The area under the receiver-operating characteristics (ROC) curve was determined for the LUS score to predict the 28-day mortality rate. The same analysis was performed for the Simplified Acute Physiology Score, left ventricular ejection fraction, cardiac output, brain natriuretic peptide and ultra-sensitive troponin levels at admission. Results: In 57 patients, the 28-day mortality rate was $21 \%$. The area under the ROC curve of the LUS score value on ICU admission was 0.68 [95\% CI 0.54-0.82; $p=0.05]$. In non-intubated patients on ICU admission $(n=40)$, the area under the ROC curves was $0.84[95 \%$ CI $0.70-0.97 ; p=0.005]$. The best cut-off of 22 corresponded to $85 \%$ specificity and $83 \%$ sensitivity.

Conclusions: LUS scores on ICU admission for SARS-CoV-2 did not efficiently predict the 28-day mortality rate. Performance was better for non-intubated patients at admission. Performance of biological cardiac markers may be equivalent to the LUS score.

Keywords: Lung ultrasound score; Echocardiography; SARS-CoV-2; Critical care

M. Boucekine

Centre d'Etudes et de Recherches Sur Les Services de Santé et Qualité, Faculté de Médecine, Aix-Marseille université, Marseille, France

L. Zieleskiewicz

Center for Cardiovascular and Nutrition Research (C2VN), Aix Marseille University, INSERM, INRA, Marseille, France

\section{Key Summary Points}

Why carry out this study?

SARS-CoV-2-related pneumonia severity is correlated with the extent of lung injury

Point-of-care thorax examination is widely performed during respiratory failure in case of intensive care unit admission

Can the lung ultrasound score at intensive care admission predict the 28-day mortality of respiratory failure related to SARS-CoV-2 pneumonia?

\section{What was learned from the study?}

The lung ultrasound score was not efficient for predicting the 28-day mortality rate on ICU admission in intubated patients

The lung ultrasound score performed better for non-intubated patients at admission

\section{DIGITAL FEATURES}

This article is published with digital features, including a summary slide, to facilitate understanding of the article. To view digital features for this article go to https://doi.org/10.6084/ m9.figshare.14179781.

\section{INTRODUCTION}

Since December 2019, the severe acute respiratory syndrome coronavirus 2 (SARS-CoV-2) outbreak has led to massive admissions of patients to intensive care units (ICUs) due to acute respiratory failure $[1,2]$. SARS-CoV-2-related acute respiratory failure is characterized by a predominant and diffuse lung injury pattern. The use of chest computed tomography (CT) scans plays a key role in diagnosing, quantifying and predicting the disease course [3-5]. 
However, access to CT scans can be challenging in patients at a high risk of viral transmission [6-8]. In this context, point-of-care ultrasound at the bedside may facilitate the management that will now be widely used in clinical practice to guide the management of acute respiratory failure $[9,10]$. Recently, lung ultrasound (LUS) patterns of patients with SARS-CoV-2 were described [11]. The findings revealed interstitial and bilateral lesions with increasing severity of B-lines for the most severely ill patients and the systematic presence of pleural irregularity [11]. The LUS score is a validated and reliable measure to characterize the severity of lung injury in acute respiratory failure $[9,12]$. Moreover, the LUS score has been associated with outcomes $[13,14]$. Moreover, ultrasonography can reduce radiation exposure in the pediatric population and pregnant women $[15,16]$.

In the ICU, the complete LUS examination associates the LUS score with transthoracic echocardiography (TTE) $[10,17,18]$. TTE may reveal cardiac dysfunction, which can worsen the condition $[19,20]$. Cardiac biomarkers evaluated on ICU admission have been associated with poor outcomes but data regarding initial echocardiographic evaluation on ICU admission are not available [21, 22].

The primary objective of our study was to assess the performance of the LUS score on ICU admission to predict the 28-day mortality rate in patients with SARS-CoV-2-related acute respiratory failure. The secondary objective was to asses the performance of thoracic ultrasound and biological markers of cardiac injry to predict mortality.

\section{METHODS}

\section{Design}

This is a multicentre, retrospective study of standard care collected data in ICUs of four university hospitals in France during the SARSCoV-2 pandemic from 15 March to 3 May 2020. The article respected STROBE statements for observational studies [23]. The study is ancillary to a previously published study comparing the
LUS score and chest computed tomography of lesions secondary to SARS-CoV-2 infection [24].

\section{Ethical considerations}

The study was approved by the Committee for Research Ethics of the French Society of Anesthesia and Intensive Care Medicine (CERAR IRB00010254-2020-062). In accordance with French law, patients were informed regarding the use of their data for publication $[25,26]$.

\section{Population}

We screened patients admitted to the ICU using a polymerase chain reaction documented SARSCoV-2 carriage in a nasopharyngeal or bronchoalveolar sample. Patients with acute respiratory failure on ICU admission, defined as dyspnoea associated with the need for oxygen therapy $\geq 31 / \mathrm{min}$ to maintain pulse oximetry $\geq 94 \%$ and/or a respiratory rate $\geq 35 \mathrm{bpm}$ and/or mechanical ventilation (either invasive or not), were included [27], and patients with an incomplete thoracic ultrasound examination or if the examination was performed $>2 \mathrm{~h}$ after ICU admission were excluded. Demographic data were extracted from institutional electronic medical files. Data of the thoracic ultrasound examination were prospectively recorded in the electronic medical file of patients.

\section{LUS score and echocardiographic examination protocol}

All LUS scores and echocardiographic examinations were performed by the physician in charge of the patient, according to the usual care. Ultrasounds were performed by level 3 operators (LUS academic teacher with several publications in the field or expert users with daily practice after appropriate teaching) $[28,29]$.

The thoracic ultrasound examination was performed according to international guidelines using a 12-region technique [9] (supplementary Fig. 1). All LUS score calculations were performed using an abdominal convex probe. The LUS score assessed alveolar consolidation, 
interstitial syndrome, pneumothorax, pleural effusion and pleural irregularity. The LUS score was calculated as the sum of point values from each scanning site (0: normal scan; 1 : moderate interstitial syndrome; 2 : severe interstitial syndrome [multiple or coalescent B lines]; 3: alveolar consolidation) [9]. Example images are provided in supplementary Fig. 1. The pleural irregularity was a qualitative definition and an estimation of the physician in charge, which was not included in the calculation of the LUS scores. A score from 0 to 36 was then calculated. As described before, we classified acute respiratory distress syndrome (ARDS) as focal if the LUS score was zero in at least four areas or as diffuse overall [30] . Pneumothorax, defined as the visualisation of symmetric pleural sliding in the anterior chest area according to international guidelines, was excluded from the analysis [31, 32]. Details of a LUS score examination are presented in supplementary Fig. 1.

An echocardiographic examination was performed on ICU admission as usual care. The examination was standardized with visual left ventricular systolic function estimation of the apical four-chamber view. Left ventricular filling pressure was recorded by pulsed-wave Doppler early mitral flow peak velocity ( $E$ wave) and late mitral flow peak velocity ( $A$ wave). Diastolic function was defined using the $E / A$ ratio. Second, we recorded the early diastolic mitral annulus displacement velocity ( $E^{\prime}$ wave) using tissue Doppler imaging. The ratio of early mitral flow peak velocity to early diastolic mitral annulus displacement velocity (E/E' ratio) was then calculated. Diastolic dysfunction was defined as the association of an $E / A$ ratio $<0.8$ with the value of the $E$ wave $<50 \mathrm{~cm} / \mathrm{s}$, according to the guidelines [33]. Elevated left ventricular filling pressure was defined by an $E$ / $E^{\prime}$ ratio $>12$, according to the guidelines [33]. The velocity time integral (VTI) was measured using pulsed Doppler in the left ventricular outflow tract (LVOT) from a five-chamber apical view . The maximal subaortic VTI was recorded independently of the respiratory cycle. Heart rate was calculated by measuring the $R-R$ distance between two successive VTIs. The LVOT surface was calculated using the measured diameter $(\mathrm{mm})$ of the LVOT squared multiplied by $\pi / 4$ using a longitudinal parasternal view. Cardiac output $(\mathrm{ml} / \mathrm{min})$ was calculated using the following formula: VTI $\times$ HR $\times$ LVOT surface.

The right ventricular systolic function was estimated using both tricuspid annular plane systolic excursion (TAPSE) and $S$ wave velocity recorded by tissue Doppler imaging at the lateral tricuspid annulus movement velocity $\left(S^{\prime}\right)$. After aligning the ultrasound cursor with the right ventricular annular plane systolic excursion, M-mode was activated to measure the TAPSE (mm), and tissue Doppler was used to measure the $S^{\prime}$ wave $(\mathrm{cm} / \mathrm{s})$. Right ventricular dysfunction was defined as TAPSE $<16 \mathrm{~mm}$ or $S^{\prime}<10 \mathrm{~cm} / \mathrm{s}$ in agreement with the current guidelines [34].

\section{Clinical features}

On ICU admission, each patient underwent a standard medical examination, including medical history, Simplified Acute Physiology Score (SAPS II) [35], Sequential Organ Failure Assessment Score [36], the concentration of plasma brain natriuretic protein, and high-sensitivity troponin and arterial lactataemia. Only the first dosages of plasmatic brain natriuretic protein and high-sensitivity troponin at admission were considered and used as markers of cardiac injury. The need for mechanical ventilation was also recorded. The ratio of arterial pressure of oxygen from the first blood gas to fractional inspired oxygen $\left(\mathrm{FiO}_{2}\right)$ was collected. In patients who received oxygen through a nasal cannula or facial mask, the $\mathrm{FiO}_{2}$ was calculated as follows: $\mathrm{FiO}_{2}=(21+3 \times$ oxygen flow (l/ min)/100) [37]. In patients who received highflow oxygen (> $40 \mathrm{l} / \mathrm{min}$ ) or non-invasive facial mask ventilation, the $\mathrm{FiO}_{2}$ was directly reported.

\section{Statistical analysis}

Patient characteristics were expressed as mean and standard deviation for quantitative variables and as numbers and per cent for qualitative variables. The area under the receiveroperating characteristic (AUC-ROC) curve for 
LUS scores was calculated to predict the occurrence of death on day 28.

The optimal threshold was calculated to discriminate occurrence of death on day 28 using the Youden index [38]. Sensitivity, specificity, negative predictive value and positive predictive value were calculated with their 95\% confidence intervals (CI). Univariate analysis was performed to compare patients' characteristics, outcomes and thoracic ultrasound variables regarding the mortality status on day 28 . Se and Sp curves were constructed to calculate the grey zone for an LUS score that was inconclusive for predicting occurrence on day 28 [39]. A grey zone represents a predictive test of low accuracy, that is, the Se and Sp are both $<90 \%$ [40]. Exploratory AUC-ROC curves were drawn for items with significant differences in univariate analysis.

Logistic regression was performed to identify the variables associated with occurrence of death on day 28. Variables with $P<0.2$ were selected from univariate analysis . Missing data were excluded from analysis.

A subgroup analysis was performed for nonintubated patients on ICU admission as previously described. Considering the retrospective and explorative nature of the study, no calculation of inclusion need was performed.

Interobserver agreement for the LUS score was evaluated from a 12-image sample randomly chosen using the intraclass correlation coefficient among the six observers (GD, FB, BA, GB, GM, LB).

For all calculations, IBM SPSS Statistics for Windows, version 20.0 software (IBM Corp., Armonk, NY) was used, and the significance level was set at $p<0.05$.

\section{RESULTS}

During the study period, 148 patients were admitted to the ICU for SARS-CoV-2. One hundred twenty-seven patients met the criteria for acute respiratory failure; of these, 57 patients received a complete thoracic ultrasound examination within the first $2 \mathrm{~h}$ after ICU admission and were analysed (flow chart, supplementary Fig. 2). Patient characteristics are shown in
Table 1. Forty-four (64\%) were male, and mean SAPS II was $36( \pm 18)$. Twelve $(21 \%)$ patients died on day 28 after ICU admission. Mean time since first symptoms was $7( \pm 4)$ days.

The characteristics of the patients on ICU admission according to the occurrence of death at day 28 are shown in Table 1. Thoracic ultrasound findings on ICU admission according to the occurrence of death at day 28 are shown in Table 2 . In the whole cohort, the LUS score was $20( \pm 5)$ in the survivors vs. $23( \pm 2)$ in the 28-day non-survivors $(p=0.06)$. Interobserver agreement was excellent with intraclass correlation of 0.91 [0.81-0.97]; $p<0.001$. The correlation matrix between observers is presented in the supplementary data. The AUC-ROC curve of the LUS value on ICU admission to predict the occurrence of death at day 28 was 0.68 [95\% CI $0.54-0.82 ; p=0.05$ ] (Fig. 1). The best prediction of the occurrence of death corresponded to specificity and sensitivity at 58\% and $75 \%$ (Youden index was 0.33), respectively, when considering a cut-off at 22 (Fig. 1). The positive predictive value, negative predictive value, positive likelihood ratio and negative likelihood ratio were $37 \%, 87 \%, 1.8$ and 0.48 , respectively. The LUS score grey zone (score of 19-26) with inconclusive values included 36 patients (63\%). An LUS score $>26$ predicted occurrence of death on day 28 with Sp $>90 \%$ and PPV of 50\% in two patients. LUS score $<19$ excluded occurrence of death on day 28 with a Se $>90 \%$ and an NPV of $89 \%$ in 19 patients.

The left ventricular ejection fraction (LVEF) was lower in the 28-day non-survivors than in the survivors $(52[ \pm 11]$ vs. $58[ \pm 7] \%$; $p=0.03)$, while cardiac output was higher (6.9 [ \pm 1.2$]$ vs. $5.7[ \pm 1.5] 1 / \mathrm{min} ; p=0.01$ ) (Table 2 ). No significant differences were found regarding the presence of elevated left ventricle filling pressure $(p=0.34)$, diastolic dysfunction $(p=0.94)$ and right ventricle systolic dysfunction $(p=0.84)$ (Table 2). Analysis of biological markers of cardiac injury showed that the occurrence of death on day 28 was associated with higher brain natriuretic peptide (247 $[ \pm 341]$ vs. $1339[ \pm 1241] \mathrm{pg} / \mathrm{ml} ; p=0.001)$ and high-sensitivity troponin I $(28[ \pm 59]$ vs. 76 $[ \pm 95] \mu \mathrm{g} / \mathrm{ml} ; p=0.05)$ concentration (Table 1 ). 
Table 1 Characteristics of patients at admission and comparison regarding condition status

\begin{tabular}{|c|c|c|c|c|}
\hline & All patients $(n=57)$ & Surviving $(n=45)$ & Dead $(n=12)$ & $p$ value \\
\hline \multicolumn{5}{|l|}{ Demographic characteristics } \\
\hline Male gender (\%) & $44(64)$ & $11(24)$ & $10(83)$ & 0.56 \\
\hline Age (years) & $62( \pm 14)$ & $59( \pm 14)$ & $72( \pm 10)$ & 0.003 \\
\hline BMI $\left(\mathrm{kg} / \mathrm{m}^{2}\right)$ & $28( \pm 6)$ & $28( \pm 6)$ & $30( \pm 6)$ & 0.23 \\
\hline \multicolumn{5}{|l|}{ Medical history } \\
\hline Hypertension (\%) & $28(49)$ & $20(44)$ & $8(67)$ & 0.17 \\
\hline Coronary disease (\%) & $10(15)$ & $6(13)$ & $4(33)$ & 0.10 \\
\hline Chronic heart failure (\%) & $5(7)$ & $3(6)$ & $2(16)$ & 0.27 \\
\hline Diabetes (\%) & $22(32)$ & $19(42)$ & $3(25)$ & 0.27 \\
\hline Smoking (\%) & $11(16)$ & $7(19)$ & $4(33)$ & 0.32 \\
\hline Obesity (\%) & $19(28)$ & $14(31)$ & $5(42)$ & 0.49 \\
\hline \multicolumn{5}{|l|}{ Clinical evaluation at admission } \\
\hline SAPS II & $36( \pm 18)$ & $35( \pm 20)$ & $42( \pm 10)$ & 0.21 \\
\hline Time since first symptom (days) & $7( \pm 4)$ & $7( \pm 4)$ & $6( \pm 4)$ & 0.90 \\
\hline SOFA & $4( \pm 3)$ & $4( \pm 3)$ & $5( \pm 3)$ & 0.20 \\
\hline SOFA respiratory & $2( \pm 1)$ & $2( \pm 1)$ & $2( \pm 1)$ & 0.72 \\
\hline MV at admission (\%) & $17(25)$ & $12(27)$ & $5(42)$ & 0.31 \\
\hline $\mathrm{PaO}_{2} / \mathrm{FiO}_{2}$ ratio $(\mathrm{mmHg})$ & $172( \pm 75)$ & $181( \pm 77)$ & $134( \pm 57)$ & 0.09 \\
\hline $\mathrm{BNP}(\mathrm{pg} / \mathrm{ml})$ & $409( \pm 658)$ & $247( \pm 341)$ & $1339( \pm 1241)$ & 0.001 \\
\hline Troponin Us $(\mu \mathrm{g} / \mathrm{ml})$ & $38( \pm 70)$ & $28( \pm 59)$ & $76( \pm 95)$ & 0.05 \\
\hline Lactataemia $(\mathrm{mmol} / \mathrm{l})$ & $1.6( \pm 0.7)$ & $1.6( \pm 0.7)$ & $1.6( \pm 0.7)$ & 0.90 \\
\hline Norepinephrine $(\mathrm{mg} / \mathrm{h})$ & $0.3( \pm 0.9)$ & $0.3( \pm 1)$ & $0.3( \pm 0.7)$ & 0.94 \\
\hline \multicolumn{5}{|l|}{ Evolution in ICU } \\
\hline Use of MV (\%) & $40(70)$ & $31(78)$ & $9(75)$ & 0.68 \\
\hline Use of prone position (\%) & $37(54)$ & $27(60)$ & $10(83)$ & 0.13 \\
\hline Use of RRT (\%) & $9(13)$ & $6(13)$ & $3(25)$ & 0.32 \\
\hline Use of ECMO (\%) & $5(7)$ & $4(8)$ & $1(8)$ & 0.95 \\
\hline MV-free days & $12( \pm 12)$ & $14( \pm 12)$ & - & \\
\hline ICU-free days & $8( \pm 10)$ & $10( \pm 10)$ & - & \\
\hline
\end{tabular}

$B M I$ body mass index, $B N P$ brain natriuretic peptide, ECMO extracorporeal membrane oxygenation, $I C U$ intensive care unit, $M V$ mechanical ventilation, $R R T$ renal replacement therapy, SAPS Simplified Acute Physiology Score, SOFA Sequential Organ Failure Assessment 
Table 2 Thoracic ultrasound findings of patients at admission and comparison regarding living status

\begin{tabular}{|c|c|c|c|c|}
\hline & All patients $(n=57)$ & $\begin{array}{l}\text { Surviving } \\
(n=45)\end{array}$ & $\begin{array}{l}\text { Dead } \\
(n=12)\end{array}$ & $p$ value \\
\hline \multicolumn{5}{|c|}{ Lung ultrasound evaluation at admission } \\
\hline Total LUS score & $20( \pm 4)$ & $20( \pm 5)$ & $23( \pm 2)$ & 0.06 \\
\hline Any consolidation (\%) & $37(65)$ & $29(64)$ & $8(67)$ & 0.88 \\
\hline Focal ARDS (\%) & $4(6)$ & $4(9)$ & $0(0)$ & 0.28 \\
\hline Pleural irregularity (\%) & $30(44)$ & $25(56)$ & $5(56)$ & 0.76 \\
\hline Pleural effusion (\%) & $4(7)$ & $1(2)$ & $3(25)$ & 0.006 \\
\hline \multicolumn{5}{|c|}{ Cardiac ultrasound evaluation at admission } \\
\hline LVEF (\%) & $56( \pm 8)$ & $58( \pm 7)$ & $52( \pm 11)$ & 0.03 \\
\hline Cardiac output $(1 / \mathrm{min})$ & $5.9( \pm 1.5)$ & $5.7( \pm 1.5)$ & $6.9( \pm 1.2)$ & 0.01 \\
\hline$E$ wave $(\mathrm{m} / \mathrm{s})$ & $0.8( \pm 0.5)$ & $0.8( \pm 0.5)$ & $0.8( \pm 0.4)$ & 0.70 \\
\hline$A$ wave $(\mathrm{m} / \mathrm{s})$ & $0.9( \pm 0.3)$ & $0.9( \pm 0.3)$ & $1( \pm 0)$ & 0.60 \\
\hline$E / A$ ratio & $1( \pm 0.2)$ & $1( \pm 0.2)$ & $1( \pm 0)$ & 1 \\
\hline$E$ wave $(\mathrm{cm} / \mathrm{s})$ & $7( \pm 4)$ & $7( \pm 5)$ & $7( \pm 4)$ & 0.85 \\
\hline$E / E$ ratio & $7( \pm 2)$ & $( \pm 3)$ & $( \pm 2)$ & 0.76 \\
\hline Diastolic dysfunction (\%) & $9(13)$ & $7(21)$ & $2(22)$ & 0.94 \\
\hline Elevated LVFP (\%) & $3(4)$ & $3(8)$ & $0(0)$ & 0.34 \\
\hline TAPSE $(\mathrm{mm})$ & $21( \pm 5)$ & $22( \pm 4)$ & $19( \pm 6)$ & 0.09 \\
\hline Tricuspid $S^{\prime}$ wave $(\mathrm{cm} / \mathrm{s})$ & $14( \pm 4)$ & $13( \pm 4)$ & $15( \pm 5)$ & 0.41 \\
\hline Right ventricle dysfunction (\%) & $6(9)$ & $5(15)$ & $1(13)$ & 0.84 \\
\hline
\end{tabular}

$A R D S$ acute respiratory distress syndrome, $L U S$ lung ultrasound score, $L V E F$ left ventricle ejection fraction, $L V F P$ left ventricle filling pressure, TAPSE tricuspid annular plane systolic excursion

The AUC-ROC curves of SAPS-II, cardiac output, LVEF, brain natriuretic peptide and high-sensitivity troponin concentration values on ICU admission to predict the occurrence of death at day 28 are presented in Fig. 2. Best prediction cut-off using the Youden index method, positive and negative predictive value and positive and negative likelihood ratio for each parameter are summarized in Table 3 .

Results of multivariate analysis are presented in Table 4. LUS score was not associated with occurrence of death on day $28(p=0.87)$. Age $(\mathrm{OR}=1.23$, IC 95\% [1.06-1.43]; $p=0.006)$ and body mass index (OR $=1.24$, IC 95\% [50]; $p=0.23)$ at admission were significantly associated with occurrence of death on day 28 .

\section{Subgroup analysis of non-intubated patients}

LUS score presents a better predictive value for non-intubated patients at admission. Details of the subgroup analysis of non-intubated patients are detailed in the supplementary data.

Comparisons between the intubated and non-intubated patients at the ICU admission are presented in supplementary Table 3 and supplementary Table 4 . 


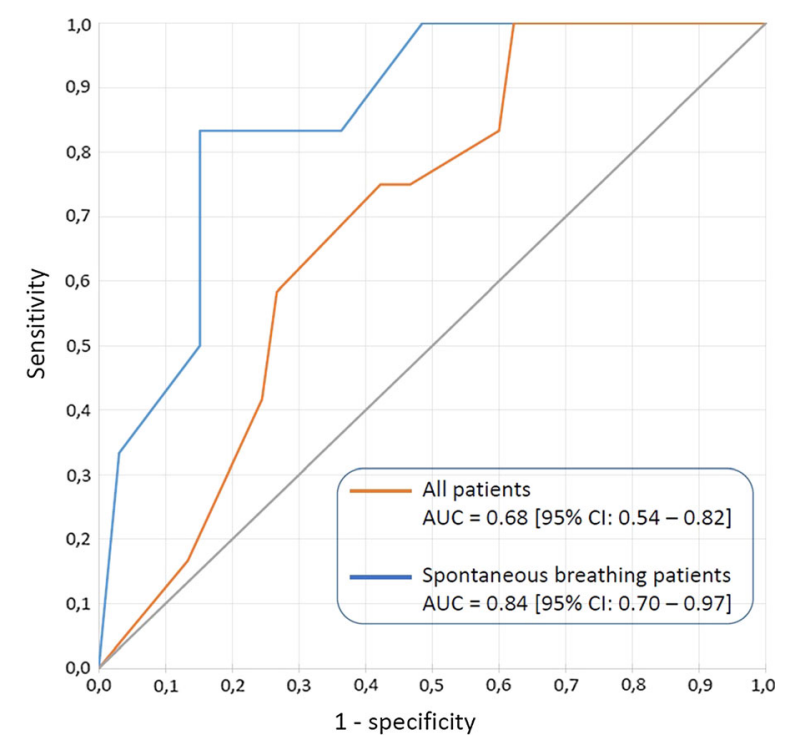

Fig. 1 Receiver-operating characteristics for the lung ultrasound score on ICU admission to predict occurrence of death at day 28. AUC Area under the curve

\section{DISCUSSION}

In this study, we found a low predictive performance of the LUS score on ICU admission for the occurrence of death at day 28 in patients with SARS-CoV-2 admitted for acute respiratory failure. The LUS score showed slightly better performance to predict the occurrence of death on day 28 with a cut-off at 22 for non-intubated patients with a negative predictive value of $96 \%$ under 19.

This discrepancy between intubated and non-intubated patients may be explained by the differences in the severity of illness and progression. Furthermore, mechanical ventilation settings and high levels of positive end-expiratory pressure may contribute in the decrease in LUS score because of a recruitment effect [41].

The ability of the LUS score to predict the 28-day death rate in non-intubated patients may be related to the severity of lung injury. Recent data suggest that the type of lung

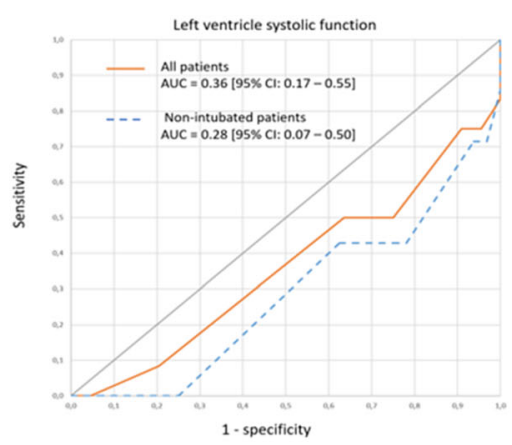

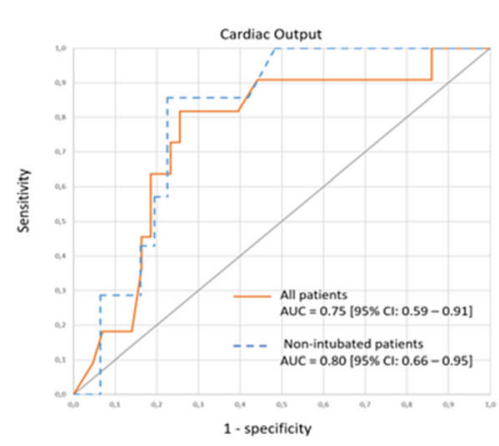

Fig. 2 Receiver-operating characteristics for cardiac output, left ventricle ejection function, brain natriuretic peptide and high-sensitivity troponin on ICU admission to predict occurrence of death at day 28. Results are

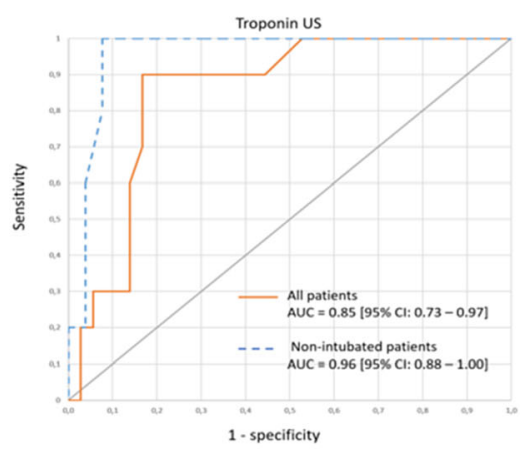

presented for the whole cohort and for the subgroup analysis of the non-intubated patients on ICU admission. $A U C$ area under the curve 
Table 3 Analysis of the New Simplified Acute Physiologic Score, cardiac output, left ventricle fraction ejection, brain natriuretic peptide and high-sensitivity troponin on intensive care unit admission to predict occurrence of death on day 28 for the whole cohort $(n=57)$ and non-intubated patients at admission $(n=40)$

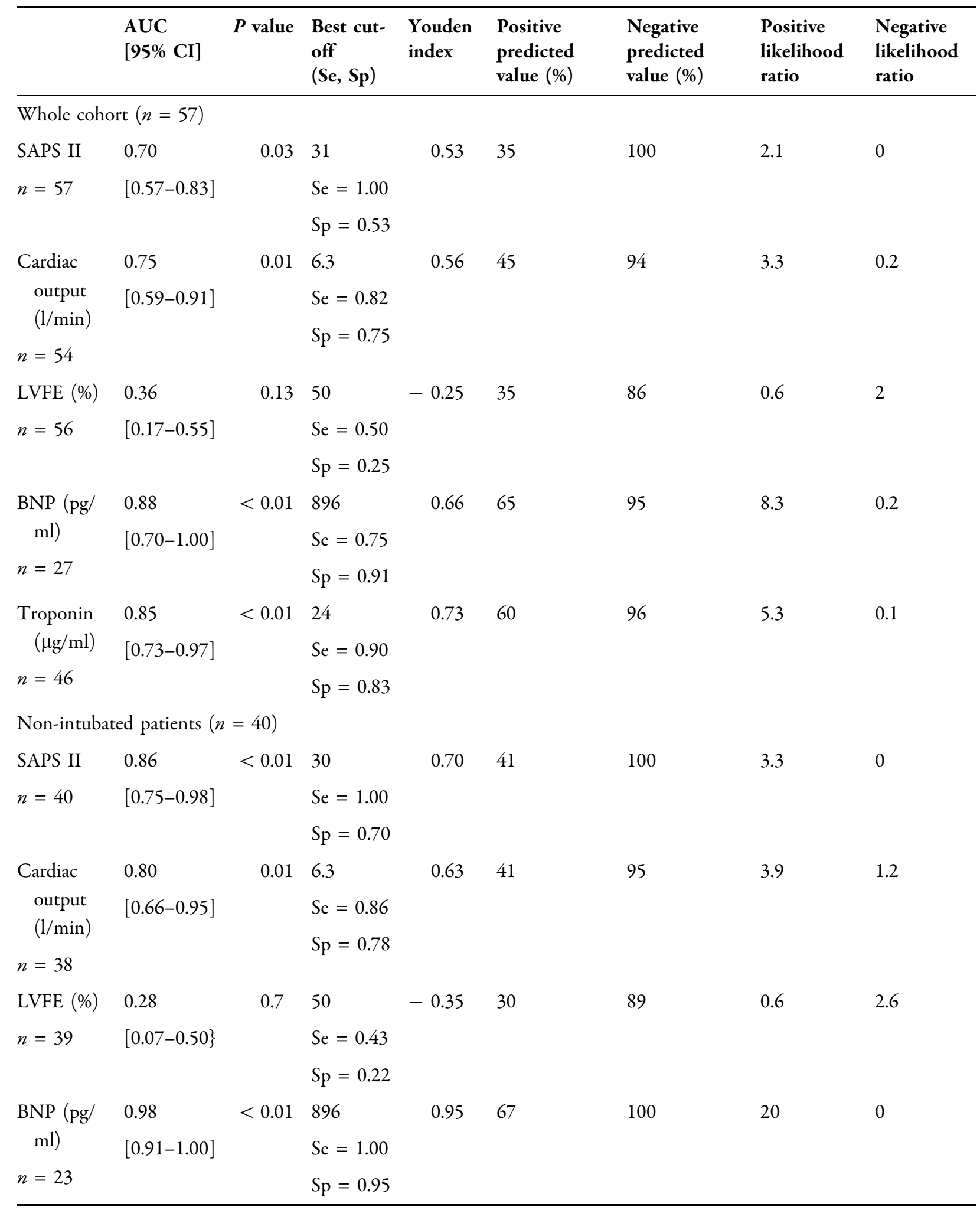


Table 3 continued

\begin{tabular}{|c|c|c|c|c|c|c|c|c|}
\hline & $\begin{array}{l}\text { AUC[95\% } \\
\mathrm{CI}]\end{array}$ & $P$ value & $\begin{array}{l}\text { Best cut- } \\
\text { off(Se, } \\
\text { Sp) }\end{array}$ & $\begin{array}{l}\text { Youden } \\
\text { index }\end{array}$ & $\begin{array}{l}\text { Positive } \\
\text { predicted } \\
\text { value (\%) }\end{array}$ & $\begin{array}{l}\text { Negative } \\
\text { predicted } \\
\text { value (\%) }\end{array}$ & $\begin{array}{l}\text { Positive } \\
\text { likelihood } \\
\text { ratio }\end{array}$ & $\begin{array}{l}\text { Negative } \\
\text { likelihood } \\
\text { ratio }\end{array}$ \\
\hline \multirow{2}{*}{$\begin{array}{l}\text { Troponin } \\
(\mu \mathrm{g} / \mathrm{ml})\end{array}$} & 0.96 & \multirow[t]{3}{*}{$<0.01$} & 24 & \multirow[t]{3}{*}{0.92} & \multirow[t]{3}{*}{67} & \multirow[t]{3}{*}{100} & \multirow[t]{3}{*}{12.5} & \multirow[t]{3}{*}{0} \\
\hline & {$[0.88-1.00]$} & & $\mathrm{Se}=1.00$ & & & & & \\
\hline$n=31$ & & & $S p=0.92$ & & & & & \\
\hline
\end{tabular}

$A U C$ area under the receiver-operating characteristic curves, SAPS Simplified Acute Physiology Score, Se sensibility, $S p$ specificity, $L V F E$ left ventricle fraction ejection, $B N P$ brain natriuretic peptide

Table 4 Results of logistic regression from the whole cohort $(n=57)$ to identify criteria at admission associated with occurrence of death on day 28

\begin{tabular}{lll}
\hline & OR [CI 95\%] & $\boldsymbol{p}$ value \\
\hline Age (years) & $1.23[1.06-1.43]$ & 0.006 \\
BMI $\left(\mathrm{kg} / \mathrm{m}^{2}\right)$ & $1.24[1.03-1.50]$ & 0.02 \\
Male gender & $1.53[0.12-18.8]$ & 0.74 \\
LUS score & $1.02[0.79-1.30]$ & 0.87 \\
Lactataemia $(\mathrm{mmol} / \mathrm{l})$ & $0.52[0.12-2.13]$ & 0.36 \\
SOFA score & $1.10[0.83-1.46]$ & 0.52 \\
\hline
\end{tabular}

BMI body mass index, LUS lung ultrasound, SOFA Sequential Organ Failure Assessment

injuries defined by CT scan on ICU admission predicted the outcome at day 5 or the admission of patients with SARS-CoV-2 to the ICU $[5,42]$. A similar approach using a point-of-care, nonirradiant and easily performed LUS seems feasible. Indeed, the location and severity of acute lung injuries evaluated with LUS appear to be correlated with the CT scan in the case of SARSCoV-2 pneumonia [3, 43, 44]. Furthermore, the correlation between the LUS score and severity of acute lung injury was previously described [13, 45-47].

Bonadia et al. performed a study evaluating the performance of the LUS score to predict mortality and ICU admission of SARS-CoV-2 patients admitted to the emergency department [14]. This study highlighted that the number of lung sectors presenting anomalies during LUS examination was correlated with prognosis [14]. These results are in line with results obtained from CT scan examination and prognosis in SARS-CoV-2-related lung infection $[3,5]$. Furthermore, these results confirmed that LUS examinations at the bedside are correlated with thoracic CT scan findings as shown in a previous multicentric observational study [24]. This discrepancy between Bonadia et al.'s findings and our results is not necessarily contradictory [14]. We can assume that the qualitative evaluation of the number of areas with abnormal LUS examinations may be more predictive than characterizing the severity of the lesion by a quantitative evaluation using the LUS score. This may reflect the spread of the lung disease, which is correlated with the prognosis as found on thoracic CT scan examination.

Our data showed the differences in the assessment of LVEF using cardiac ultrasound. There was a decreased LVEF in non-survivors, while an increased cardiac output was associated with an increased 28-day death rate, as previously described [48]. High-sensitivity troponin and brain natriuretic peptide concentrations on admission were also associated with the outcome. These findings are in line with the association between increases in cardiac injury biomarkers and poor outcomes in patients with SARS-CoV-2 [21, 22, 49]. We assume that the discrepancy between intubated and non-intubated patients may be due to the heart-lung interaction during mechanical ventilation [50]. These findings support the interest in a combined evaluation of the lungs and cardiac 
function to evaluate the prognosis. Of note, our study showed no abnormal marker of the right ventricular systolic function. However, considering the high incidence of thrombotic events in the severe SARS-CoV-2 population, exploration of the veins of the lower limbs could be useful $[51,52]$. The LUS score was not more efficient than SAPS II, which showed comparable ROC curves to predict the occurrence of death on day 28. Ultrasound assessment of patients' severity could not rule out basic clinical and biological examination. Its added value may rather lie in the therapeutic orientation in patients with respiratory insufficiency whose origin can be multifactorial.

Our study has several limitations. First, only a few patients were intubated and the heterogeneity may limit our conclusions. However, the high number of non-intubated patients on ICU admission may help improve the triage at an early stage of management of SARS-CoV-2related acute respiratory failure, notably outside the ICU ward. Second, the design was retrospective, which may be a source of bias in selection of patients who received a LUS examination. Third, missing data regarding biological markers of cardiac injury may have underpowered the related analysis. Lastly, the number of analyzed patients remains low despite the multicentric character of the study.

\section{CONCLUSION}

The LUS score on ICU admission due to SARSCoV-2 pneumonia-related acute respiratory failure was not efficient to predict the occurrence of death at day 28 . Performance of biological cardiac markers may be similar to that of the LUS score.

\section{ACKNOWLEDGEMENTS}

Fundings. No funding or sponsorship was received for this study or publication of this article.
Authorship. All named authors meet the International Committee of Medical Journal Editors (ICMJE) criteria for authorship for this article, take responsibility for the integrity of the work as a whole, and have given their approval for this version to be published.

Disclosures. Laurent Zieleskiewicz declares receiving fees from General Electric Healthcare. Gary Duclos, Florian Bazalguette, Bernard Allaouchiche, Neyla Mohammedi, Alexandre Lopez, Mathieu Gazon, Guillaume Besch, Lionel Bouvet, Laurent Muller, Gauthier Mathon, Charlotte Arbelot, Mohamed Boucekine and Marc Leone have nothing to disclose.

Compliance with Ethics Guidelines. The study was approved by the Committee for Research Ethics of the French Society of Anesthesia and Intensive Care Medicine (CERAR IRB00010254-2020-062). In accordance with French law, patients were informed regarding the use of their data for publication $[25,26]$.

Data Availability. The datasets generated during and/or analyzed during the current study are available from the corresponding author on reasonable request.

\section{REFERENCES}

1. Richardson S, Hirsch JS, Narasimhan M, Crawford JM, McGinn T, Davidson KW, et al. Presenting characteristics, comorbidities, and outcomes among 5700 patients hospitalized with COVID-19 in the New York City Area. JAMA. 2020;323(20): 2098.

2. Grasselli G, Zangrillo A, Zanella A, Antonelli M, Cabrini L, Castelli A, et al. Baseline characteristics and outcomes of 1591 patients infected with SARSCoV-2 admitted to ICUs of the Lombardy Region, Italy. JAMA. 2020;323(16):1574-81.

3. Yang Y, Huang Y, Gao F, Yuan L, Wang Z. Lung ultrasonography versus chest CT in COVID-19 pneumonia: a two-centered retrospective comparison study from China. Intensive Care Med. 2020;46(9):1761-3.

4. Wu J, Wu X, Zeng W, Guo D, Fang Z, Chen L, et al. Chest CT findings in patients with coronavirus 
disease 2019 and its relationship with clinical features. Invest Radiol. 2020;55:257-61.

5. Colombi D, Bodini FC, Petrini M, Maffi G, Morelli $\mathrm{N}$, Milanese $\mathrm{G}$, et al. Well-aerated lung on admitting chest $\mathrm{CT}$ to predict adverse outcome in COVID-19 Pneumonia. Radiology. 2020;296(2): E86-E96.

6. Yousuf B, Sujatha KS, Alfoudri H, Mansurov V. Transport of critically ill COVID-19 patients. Intensive Care Med. 2020;46(8):1663-4.

7. Aliaga M, Forel J-M, De Bourmont S, Jung B, Thomas G, Mahul M, et al. Diagnostic yield and safety of CT scans in ICU. Intensive Care Med. 2015;41: 436-43.

8. Buonsenso D, Pata D, Chiaretti A. COVID-19 outbreak: less stethoscope, more ultrasound. Lancet Respir Med. 2020;8:e27.

9. Volpicelli G, Elbarbary M, Blaivas M, Lichtenstein DA, Mathis G, Kirkpatrick AW, et al. International evidence-based recommendations for point-of-care lung ultrasound. Intensive Care Med. 2012;38: 577-91.

10. Zieleskiewicz L, Muller L, Lakhal K, Meresse Z, Arbelot C, Bertrand P-M, et al. Point-of-care ultrasound in intensive care units: assessment of 1073 procedures in a multicentric, prospective, observational study. Intensive Care Med. 2015;41:1638-47.

11. Xing C, Li Q, Du H, Kang W, Lian J, Yuan L. Lung ultrasound findings in patients with COVID-19 pneumonia. Crit Care Lond Engl. 2020;24:174.

12. Volpicelli G. Lung sonography. J Ultrasound Med Off J Am Inst Ultrasound Med. 2013;32:165-71.

13. Markarian T, Zieleskiewicz L, Perrin G, Claret P-G, Loundou A, Michelet P, et al. A lung ultrasound score for early triage of elderly patients with acute dyspnea. CJEM. 2019;21:399-405.

14. Bonadia N, Carnicelli A, Piano A, Buonsenso D, Gilardi E, Kadhim C, et al. Lung ultrasound findings are associated with mortality and need for intensive care admission in COVID-19 patients evaluated in the emergency department. Ultrasound Med Biol. 2020;46:2927-37.

15. Nino G, Zember J, Sanchez-Jacob R, Gutierrez MJ, Sharma K, Linguraru MG. Pediatric lung imaging features of COVID-19: a systematic review and meta-analysis. Pediatr Pulmonol. 2021;56:252-63.

16. Juan J, Gil MM, Rong Z, Zhang Y, Yang H, Poon LC. Effect of coronavirus disease 2019 (COVID-19) on maternal, perinatal and neonatal outcome: systematic review. Ultrasound Obstet Gynecol Off J Int Soc Ultrasound Obstet Gynecol. 2020;56:15-27.

17. Bataille B, Riu B, Ferre F, Moussot PE, Mari A, Brunel $\mathrm{E}$, et al. Integrated use of bedside lung ultrasound and echocardiography in acute respiratory failure: a prospective observational study in ICU. Chest. 2014;146:1586-93.

18. Staub LJ, Mazzali Biscaro RR, Kaszubowski E, Maurici R. Lung ultrasound for the emergency diagnosis of pneumonia, acute heart failure, and exacerbations of chronic obstructive pulmonary disease/asthma in adults: a systematic review and meta-analysis. J Emerg Med. 2019;56:53-69.

19. Silva S, Biendel C, Ruiz J, Olivier M, Bataille B, Geeraerts T, et al. Usefulness of cardiothoracic chest ultrasound in the management of acute respiratory failure in critical care practice. Chest. 2013;144: 859-65.

20. Mojoli F, Bouhemad B, Mongodi S, Lichtenstein D. Lung ultrasound for critically Ill patients. Am J Respir Crit Care Med. 2019;199:701-14.

21. Guo T, Fan Y, Chen M, Wu X, Zhang L, He T, et al. Cardiovascular implications of fatal outcomes of patients with coronavirus disease 2019 (COVID-19). JAMA Cardiol. 2020;5(7):811-8.

22. Shi S, Qin M, Cai Y, Liu T, Shen B, Yang F, et al. Characteristics and clinical significance of myocardial injury in patients with severe coronavirus disease 2019. Eur Heart J. 2020;41(22):2070-9.

23. von Elm E, Altman DG, Egger M, Pocock SJ, Gøtzsche PC, Vandenbroucke JP, et al. The strengthening the reporting of observational studies in epidemiology (STROBE) statement: guidelines for reporting observational studies. J Clin Epidemiol. 2008;61:344-9.

24. Zieleskiewicz L, Markarian T, Lopez A, Taguet C, Mohammedi N, Boucekine $\mathrm{M}$, et al. Comparative study of lung ultrasound and chest computed tomography scan in the assessment of severity of confirmed COVID-19 pneumonia. Intensive Care Med. 2020;46:1707-13.

25. Toulouse E, Masseguin C, Lafont B, McGurk G, Harbonn A, Roberts JA, et al. French legal approach to clinical research. Anaesth Crit Care Pain Med. 2018;37:607-14.

26. Toulouse E, Lafont B, Granier S, Mcgurk G, Bazin $\mathrm{J}$-E. French legal approach to patient consent in clinical research. Anaesth Crit Care Pain Med. 2020;39:883-5.

27. Recommandations d'experts portant sur la prise en charge en réanimation des patients en période 
d'épidémie à SARS-CoV2. Société Fr. D'Anesthésie Réanimation. 2020. Available from: https://sfar.org/ recommandations-dexperts-portant-sur-la-prise-encharge-en-reanimation-des-patients-en-periodedepidemie-a-sars-cov2/. Accessed 4 March 2021.

28. Arbelot C, Dexheimer Neto FL, Gao Y, Brisson H, Chunyao W, Lv J, et al. Lung ultrasound in emergency and critically Ill patients: number of supervised exams to reach basic competence. Anesthesiology. 2020;132:899-907.

29. Expert Round Table on Echocardiography in ICU. International consensus statement on training standards for advanced critical care echocardiography. Intensive Care Med. 2014;40:654-66.

30. Haddam M, Zieleskiewicz L, Perbet S, Baldovini A, Guervilly C, Arbelot C, et al. Lung ultrasonography for assessment of oxygenation response to prone position ventilation in ARDS. Intensive Care Med. 2016;42:1546-56.

31. Mayo PH, Copetti R, Feller-Kopman D, Mathis G, Maury E, Mongodi S, et al. Thoracic ultrasonography: a narrative review. Intensive Care Med. 2019;45:1200-11.

32. Lichtenstein DA. BLUE-protocol and FALLS-protocol: two applications of lung ultrasound in the critically ill. Chest. 2015;147:1659-70.

33. Nagueh SF, Smiseth OA, Appleton CP, Byrd BF, Dokainish H, Edvardsen T, et al. Recommendations for the evaluation of left ventricular diastolic function by echocardiography: an update from the American Society of Echocardiography and the European Association of Cardiovascular Imaging. Eur Heart J Cardiovasc Imaging. 2016;17:1321-60.

34. Rudski LG, Lai WW, Afilalo J, Hua L, Handschumacher MD, Chandrasekaran K, et al. Guidelines for the echocardiographic assessment of the right heart in adults: a report from the American Society of Echocardiography endorsed by the European Association of Echocardiography, a registered branch of the European Society of Cardiology, and the Canadian Society of Echocardiography. J Am Soc Echocardiogr Off Publ Am Soc Echocardiogr. 2010;23:685-713 (quiz 786-8).

35. Le Gall JR, Lemeshow S, Saulnier F. A new Simplified Acute Physiology Score (SAPS II) based on a European/North American multicenter study. JAMA. 1993;270:2957-63.

36. Vincent JL, Moreno R, Takala J, Willatts S, De Mendonça A, Bruining $\mathrm{H}$, et al. The SOFA (Sepsisrelated Organ Failure Assessment) score to describe organ dysfunction/failure. On behalf of the Working Group on Sepsis-Related Problems of the
European Society of Intensive Care Medicine. Intensive Care Med. 1996;22:707-10.

37. Frat J-P, Thille AW, Mercat A, Girault C, Ragot S, Perbet $S$, et al. High-flow oxygen through nasal cannula in acute hypoxemic respiratory failure. N Engl J Med. 2015;372:2185-96.

38. Youden WJ. Index for rating diagnostic tests. Cancer. 1950;3:32-5.

39. Ray P, Le Manach Y, Riou B, Houle TT. Statistical evaluation of a biomarker. Anesthesiology. 2010;112:1023-40.

40. Coste J, Pouchot J. A grey zone for quantitative diagnostic and screening tests. Int $\mathrm{J}$ Epidemiol. 2003;32:304-13.

41. Bouhemad B, Brisson H, Le-Guen M, Arbelot C, Lu Q, Rouby J-J. Bedside ultrasound assessment of positive end-expiratory pressure-induced lung recruitment. Am J Respir Crit Care Med. 2011;183: 341-7.

42. Mahdjoub E, Mohammad W, Lefevre T, Debray M-P, Khalil A, Study Group. Admission chest CT score predicts 5-day outcome in patients with COVID-19. Intensive Care Med. 2020;46(8): 1648-50.

43. Duclos G, Lopez A, Leone M, Zieleskiewicz L. "No dose" lung ultrasound correlation with "low dose" CT scan for early diagnosis of SARS-CoV-2 pneumonia. Intensive Care Med. 2020;46(6):1103-4.

44. Zieleskiewicz L, Duclos G, Dransart-Rayé O, Nowobilski N, Bouhemad B. Ultrasound findings in patients with COVID-19 pneumonia in early and late stages: Two case-reports. Anaesth Crit Care Pain Med. 2020;39(3):391-2.

45. Leblanc D, Bouvet C, Degiovanni F, Nedelcu C, Bouhours G, Rineau E, et al. Early lung ultrasonography predicts the occurrence of acute respiratory distress syndrome in blunt trauma patients. Intensive Care Med. 2014;40:1468-74.

46. Soummer A, Perbet S, Brisson H, Arbelot C, Constantin J-M, Lu Q, et al. Ultrasound assessment of lung aeration loss during a successful weaning trial predicts postextubation distress*. Crit Care Med. 2012;40:2064-72.

47. Xirouchaki N, Magkanas E, Vaporidi K, Kondili E, Plataki M, Patrianakos A, et al. Lung ultrasound in critically ill patients: comparison with bedside chest radiography. Intensive Care Med. 2011;37:1488-93.

48. Bergenzaun L, Gudmundsson P, Öhlin H, Düring J, Ersson A, Ihrman L, et al. Assessing left ventricular systolic function in shock: evaluation of 
echocardiographic parameters in intensive care. Crit Care Lond Engl. 2011;15:R200.

49. Kwenandar F, Japar KV, Damay V, Hariyanto TI, Tanaka M, Lugito NPH, et al. Coronavirus disease 2019 and cardiovascular system: a narrative review. Int J Cardiol Heart Vasc. 2020;29:100557.

50. Pinsky MR. Heart lung interactions during mechanical ventilation. Curr Opin Crit Care. 2012;18:256-60.
51. Cui S, Chen S, Li X, Liu S, Wang F. Prevalence of venous thromboembolism in patients with severe novel coronavirus pneumonia. J Thromb Haemost JTH. 2020;18(6):1421-4.

52. Tang N, Bai H, Chen X, Gong J, Li D, Sun Z. Anticoagulant treatment is associated with decreased mortality in severe coronavirus disease 2019 patients with coagulopathy. J Thromb Haemost JTH. 2020;18(5):1094-9. 